\title{
AC 2008-642: ANALYSIS OF APPLICANT DATA TO IMPROVE RECRUITMENT OF FEMALE AND UNDERREPRESENTED ENGINEERING STUDENTS
}

\section{Douglas Cleary, Rowan University}

Douglas Cleary is an Associate Professor in the Civil and Environmental Engineering Department at Rowan University. His research interests are in structural engineering and education. He is a member of ACI Committees 408 and E802. In addition, his is the Affiliate Director for Project Lead the Way in New Jersey.

\section{William Riddell, Rowan University}

William Riddell is an Assistant Professor in the Civil and Environmental Engineering Department at Rowan University. His research and teaching interests include design, structural mechanics, transportation safety, energy efficiency and clean energy generation. Prior to Rowan University, he worked for the US Department of Transportation Research and Special Program

Administration, and was a National Research Council Postdoctoral Fellow in the Mechanics of Materials Branch at NASA Langley Research Center.

\section{Harriet Hartman, Rowan University}

Harriet Hartman (B.A., UCLA; M.A., University of Michigan; Ph.D., Hebrew University of Jerusalem) is Professor of Sociology at Rowan University. Her research interests include sociology and science, gender roles, and Jewish studies. She is currently President of the Association for the Social Scientific Study of Jewry. Together with with Moshe Hartman, she coauthored articles on gender and engineering appearing in Sex Roles, the Journal of Engineering Education and the Journal of Women and Minorities in Science and Engineering, and their paper won the Best Paper Award from WIED and PIC IV at ASEE, 2005. She is currently guest-editing the 2009 volume of Research in Social Problems and Public Policy on bridging between the social sciences and other sciences, technological, and engineering fields. 


\title{
Analysis of Applicant Data to Improve Recruitment of Female and Underrepresented Engineering Students
}

\begin{abstract}
Rowan University is known for its quality engineering programs. However, the numbers of female and minority students entering the engineering program are below national averages and have been declining over the past several years. Targeted recruiting efforts were proposed as an effective approach to reversing this trend. However, for targeted recruiting to be effective, a better understanding of the demographics of the applicant pool was needed. This paper reports the results of a detailed demographic analysis of applicants to the engineering program at Rowan University. The purpose of the analysis was to achieve a more complete understanding of the demographics of the applicants in order to identify data trends related to gender, ethnic background, Scholastic Achievement Test (SAT) test scores, high school attended, and socioeconomic factors. The data used in the study includes over 4800 applicants to the engineering program from 2000 to 2007 . In addition to the factors noted above, the applicants were categorized as having applied, receiving an offer from the engineering program, and having made a deposit to attend. Key findings are presented for

- Applicant rates for women and minorities versus the offer and deposit rates for these groups;

- Gender trends in high schools from which there was a large applicant pool;

- Socioeconomic trends in applicants, offers, and deposits;

- Comparative trends in SAT scores among gender, ethnic, and socioeconomic groups.
\end{abstract}

Plans for targeted recruitment efforts resulting from this study are also presented.

\section{Introduction}

Rowan University is a well-regarded comprehensive regional university located in New Jersey. The engineering program is highly ranked ${ }^{1}$ and has a proven record of retaining the female engineering students it attracts ${ }^{2}$. However, the number of female students entering the engineering program is below national averages and has been declining over the past several years, as shown in Figure 1. In the U.S. and Canada on average just under $20 \%$ of the students in engineering are female ${ }^{4}$. At Rowan University this percentage is below $15 \%$. Over the past several years female enrollment in engineering has dropped at both Rowan University and nationally.

The low numbers are a concern to the faculty. In response, four approaches to increasing the female engineering population at Rowan University were proposed. These included improved advertising, direct outreach to female high school students, interaction with guidance counselors, and adjustments to admissions and financial aid processes. At the same time it was noted minority enrollment is also low and although not all of the causes are the same, these initiatives could also be adapted for improved minority recruitment. 
It was felt that these efforts would be more effective if they were targeted to populations where they would have the best chance for success or to populations where there were identifiable weaknesses to overcome. Therefore, a better understanding of the existing applicant pool and the students who ultimately enroll was needed. The purpose of this study was to analyze the demographics of the applicants and their enrollment yields. The parameters used in the study were gender, standardized test scores, high school class rank and high school grade point average (GPA), high school, and socioeconomic conditions of the area the high school draws students from. These data would then be used to suggest future targeted recruiting and outreach efforts.

A myriad of factors distinguish one engineering program from another and these factors will play a part in shaping the makeup of the student body. Therefore, a second purpose of this work was to start a dialogue to determine systemic differences between different types of schools (e.g. public versus private, size, region, academic programs offered) and how these differences can effect recruitment of students. It is anticipated that developing demographic studies such as this for a wide assortment of engineering programs will begin to illuminate trends in female and minority enrollments. Importantly, understanding these trends might help to increase national enrollments, identify best practices, and help to indentify realistic goals.

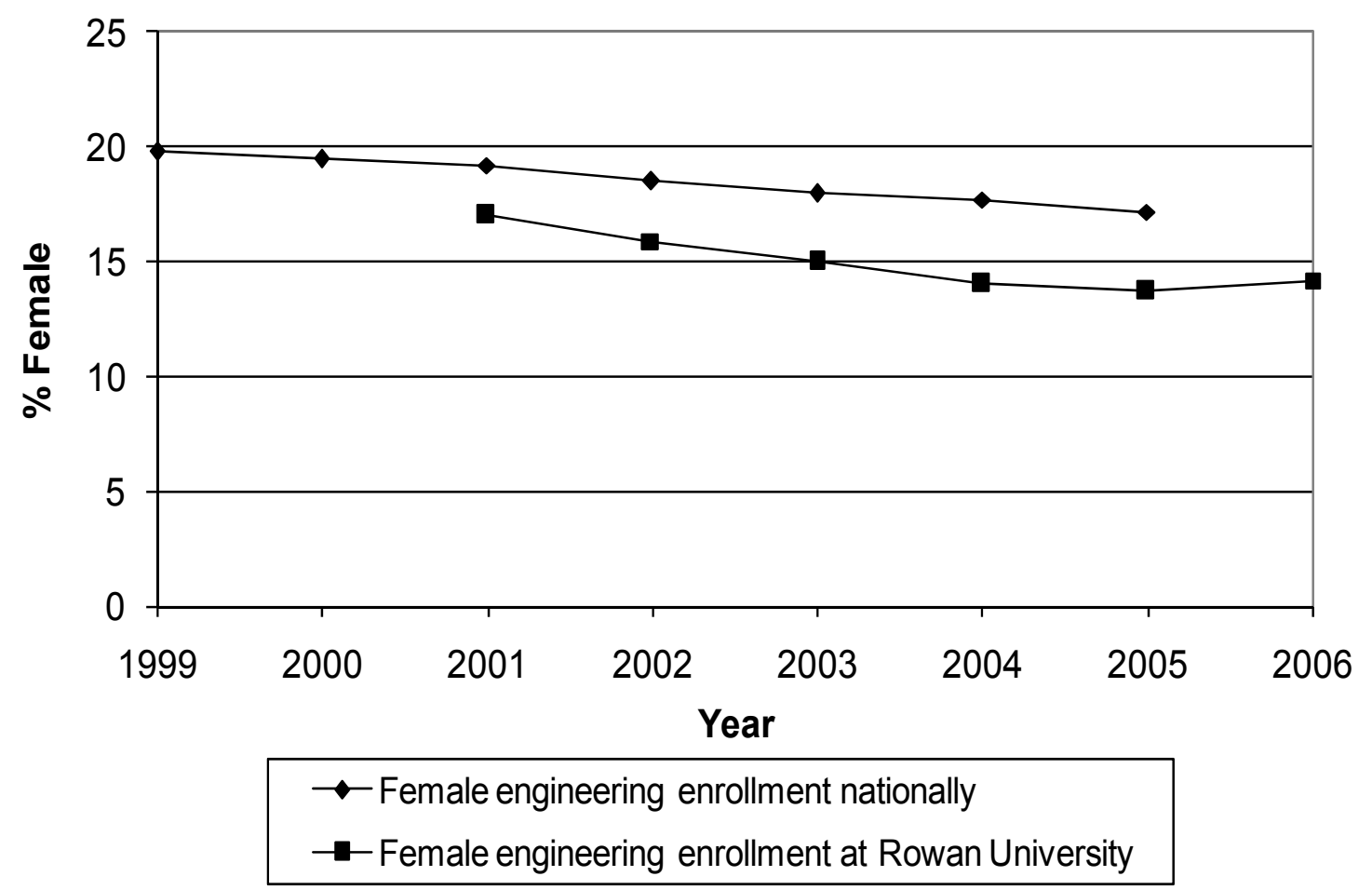

Figure 1. Comparison of undergraduate engineering degrees awarded to women nationally ${ }^{9}$ and female enrollment in engineering at Rowan University.

\section{Setting of the Study}

Enrollment trends of female students nationally and at Rowan University are similar in that both are falling (Figure 1); however, at Rowan University there is a lower percentage of female 
engineering students than the national average. The college offers degrees in civil and environmental, chemical, electrical and computer, and mechanical engineering. National trends are that degrees are awarded to women in these fields at $22 \%, 36 \%, 14 \%$, and $13 \% 5$. It is recognized that enrollment percentages and degrees awarded are not a perfect match, however, given that enrollments in these majors at the college are approximately equal, matching the national average based on these fields requires female enrollment at approximately $21 \%$.

Rowan University is a public, regional, comprehensive University which draws the vast majority of its students from within the state. As a public entity the university has less flexibility to use the admissions process to shape its student body in comparison to a private school but there is some flexibility, as discussed later.

Rowan University has been named among the 100 best values in public higher education by Kiplinger's Personal Finance magazine. In its February 2007 issue, Kiplinger's ${ }^{1}$ ranked it 81st among the "100 Best Values in Public Colleges." Additionally, the university this year was ranked 54th as a bargain for out-of-state tuition. U.S. News \& World Report ${ }^{2}$ continues to highly rank the College of Engineering. From the 2006 to 2007 "Best Colleges" edition, the engineering program was 20th among the nation's best undergraduate engineering programs whose highest degree is a bachelor's or master's. In the two most recent editions, the Chemical, Mechanical, Civil, and Electrical and Computer engineering programs have ranked as high as third, 10th, 11th and 14th in the nation, respectively. The most recent data show an $89 \%$ firstyear retention rate from 2005 to 2006 and an $80 \%$ six-year graduation rate for the students who entered the program in 2000 . Both of these numbers are well above national averages. Clearly, the engineering programs at Rowan University are of high quality and have a great deal of success with the students that enroll.

Studies $^{3}$ by Hartman and Hartman have also shown that the engineering programs specifically support the success of female engineering students who enroll. Traditionally, females leave engineering programs at higher rates than male students and complain of marginalization, alienation, discomfort, and loss of interest ${ }^{10}$. In contrast, in comparison to the male students, the female students in Rowan's engineering program:

- Are as active or more in academic enrichment activities, counseling and mentoring activities, study group activities, and student chapters of professional organizations

- Are as satisfied or more with the program's opportunities and offerings, the course workload, the laboratory work, the clinic program, the teamwork emphasis, the facultystudent relationships, and the peer relationships

- Have as high or higher academic achievement both overall and in engineering

- Have as high or higher retention throughout the program (first-year to second year, second-year to third-year, third-year to fourth-year, fourth-year to graduation).

The engineering curriculum has a strong emphasis on teamwork and project-based learning, which are frequently cited as being best practices in engineering education. These are also found 
to be supportive to retention of women in engineering ${ }^{7}$. In addition, the engineering programs have made significant efforts to be a place supportive of women engineers. The college provides active role models on the faculty, with $22 \%$ of the faculty members as well as the Dean of Engineering being female.

The issue for this engineering program is therefore not retention of the female engineering students who enroll. The historic and growing problem is attracting this population of students to a program that has proven to be a positive environment for the female students who choose to enroll.

While a comprehensive study on minority students has not been performed, the faculty is equally concerned about the number of minority students in engineering at Rowan University. The situation with regard to minority enrollment is at even greater odds from the national average, yet minorities are an important resource for diversity and enrichment both in the academy and in the engineering workforce ${ }^{11}$. Efforts to better recruit the missing population into this environment are likely to be rewarded with a larger number of graduating female and minority engineers.

With the purpose of identifying targeted recruiting efforts and maximizing their effectiveness, a series of questions was formulated about the applicant pool to the college of engineering.

1. Are female and minority applicants being attracted at a suitable rate?

2. Are these applicants accepted at the same rate as the male or white applicants?

3. Do the accepted female or minority applicants choose to enroll at the same rate as the accepted male applicants?

4. Are there significant differences between the white male and underrepresented groups?

5. From which high school or other regional measure are larger numbers of applicants coming?

6. Are there certain schools or districts or zip code regions where discrepancies are noted between numbers of male and female applicants (for instance high numbers of male applicants but proportionally few female applicants or vice versa)?

7. Which schools have historically provided a larger number of female applicants?

8. Are there schools from which a large number of female applicants come who ultimately do not enroll?

Answers to these questions can be used as guides to where proposed recruiting initiatives should be applied. Targeted recruiting and outreach makes little sense until questions such as these have been posed and answered.

\section{Data Used in the Study}

The applicant data used in the study were provided by the admissions office and were from the years 2000 to 2007 . The information considered for each applicant included engineering major, gender, ethnic group, application status, Scholastic Achievement Test ${ }^{13}$ (SAT) verbal, math, and total score, high school grade point average (GPA) and class rank, high school name. The specific data collected by admissions each year changed over the period included in the study. Data for every field evaluated in the work was not available for every applicant because at times 
it was not recorded on the application or the applicant chose not to report it. A total of 4848 applicants are included in the study of which gender information was not available for 30 applicants and ethnic data was not available for 207 applicants. A change in database management systems in the admissions office resulted in the loss of the high school data for all year 2000 applicants (525). In addition, there was no high school attended information available for approximately $25 \%$ of the applicants in subsequent years. The cause of this is not completely clear, although known causes include home schooled students, names of out-of-state high schools not being recorded by admissions, and students applying from a community college. The missing high school data primarily impacts the analysis of socioeconomic factors. For the bulk of the analysis all minorities were grouped together.

Socioeconomic factors were considered in the study using the District Factor Group (DFG) assigned to each public school district in New Jersey ${ }^{6}$. Each high school was matched to its public school district and given the DFG code for the district. As described by the New Jersey Department of Education, the District Factor Groups were first developed for the purpose of comparing students' performance on statewide assessments across demographically similar school districts. The DFGs represent an approximate measure of a community's relative socioeconomic status (SES). The classification system provides a useful tool for examining student achievement and comparing similarly-situated school districts in other analyses. The DFGs were calculated using the following six variables that are closely related to SES:

1) Percent of adults with no high school diploma

2) Percent of adults with some college education

3) Occupational status

4) Unemployment rate

5) Percent of individuals in poverty

6) Median family income.

The DFG's are designated from A to J (with some letters grouped together) ranging from the lowest economic conditions (A) to the most affluent districts (J). The DFG for each high school in New Jersey was noted, and appropriate DFG labels were appended to the applicant data set.

\section{Findings}

The purpose of this work is to determine where to target special recruitment efforts to address diversity issues in the college of engineering. To develop these plans a better understanding of where the current student body comes from is important. The data presented here begins with the basic statistics of the gender and ethnic makeup of applicants to the college of engineering, the decisions made regarding those applicants, and the subsequent decisions the accepted applicants make. This is followed by findings related to socioeconomic factors and analysis of the study variables.

Application rates, accept rates, and yield

The initial question asked was at what rate the college was attracting female and minority applicants. A breakdown of applicants by gender and minority status is provided in Table 1 . In 
the table the acceptance percentage is defined as the percentage of admittance offers made to applicants and the yield is defined as the percentage of deposits paid to offers made. Note that the subgroup columns do not add up to the total due to unreported data for individual applicants.

Table 1. Statistical comparison of applicant groups.

\begin{tabular}{|c|c||c|c||c|c|}
\hline & Total & Male & Female & White & Minority \\
\hline Applicants & 4848 & 4190 & 628 & 3727 & 895 \\
\hline Applicants (\%) & & 87.0 & 13.0 & 80.6 & 19.4 \\
\hline Offers & 2780 & 2362 & 407 & 2358 & 313 \\
\hline Accept Rate (\%) & 57.3 & 56.4 & 64.8 & 63.3 & 35.0 \\
\hline Deposits Paid & 1146 & 997 & 149 & 1026 & 102 \\
\hline Yield (\%) & 41.2 & 42.2 & $36.6^{*}$ & 43.5 & $32.6^{+}$ \\
\hline
\end{tabular}

*T-test between men and women statistically significant at $\mathrm{p}<0.05$

${ }^{+} \mathrm{T}$-test between white and minority statistically significant at $\mathrm{p}<0.001$

The proportion of females applying is very low. Women receive offers to attend at a higher rate than male applicants but accept the offers at a lower rate than male applicants. The result of this is that $13 \%$ of the applicants are female, $14.7 \%$ of the offers made are to women, and $13 \%$ of the applicants who make a deposit are female. The higher acceptance rate for women is counteracted by a lower yield. In considering this in terms of increasing the number of female students in engineering, efforts need to focus on increasing the number of female applicants and the yield.

Minorities make up $19.4 \%$ of the applicants but are only accepted at a $35 \%$ rate versus a $63.3 \%$ rate for white/Caucasian applicants. Minority applicants also accept offers to attend at a much lower rate than white/Caucasian applicants. The result of these trends is that while $19.4 \%$ of the applicants are minorities, only approximately $9 \%$ of the deposits are from minority applicants.

Returning to the original questions asked by the investigators, 1) "Are female and minority applicants being attracted at a suitable rate?" the answer is clearly no. The number of female applicants is below national averages for female enrollment. The number of minority applicants is higher but is not representative of enrollment in New Jersey High Schools where the white student population is approximately $62 \%{ }^{8}$. The base data also shows there are differences in the rates female and minority students are accepted and the yield from these groups relative to male or white applicants.

\section{Significant differences among the applicants}

The next question asked was whether the college was attracting male, female, and minority applicants who differed in any significant ways from each other and whether these differences could explain the discrepancies in the acceptance and yield rate. Results of the analysis are provided in Tables 2 and 3.

It was found that women and men who apply differ in 
- Their high school gpa--Men's gpa: 3.42; women's 3.64 t-test significant at $\mathrm{p}<.001$ and their math SATs - men's higher, 609.7; women's 598.2 — t-test significant at $\mathrm{p}=.005$.

- Their socioeconomic status (as measured by DFG). Converting the letters to numerical levels, from $A=1$ to $\mathrm{J}=8$, the mean $\mathrm{DFG}$ for men=4.5; women=4.1 (t-test significant at $\mathrm{p}<.001)$. The engineering program is attracting women coming from schools with a somewhat lower SES.

- Their minority status: $27.8 \%$ of women are minority compared to $18.0 \%$ of men (t-test significant at $\mathrm{p}<.001)$.

- Offers were made to $65 \%$ of the women compared to $56 \%$ of the men, a t-test of which is significant at $\mathrm{p}<.001$.

More significant differences are found when considering the minority applicants. The mean high school GPA and rank, and SAT scores for both math and verbal were all found to be lower for minority applicants compared to white/Caucasian applicants. Details of the comparison are shown in Table 3.

Table 2. APPLICANTS TO ENGINEERING by Gender and Mean High School Grade Point Average (HS GPA), Mean High School Rank, Mean SAT Scores, Mean Socio-economic Status of High School (DFG), and Percent Minority

\begin{tabular}{|l|l|l|}
\hline & Male & Female \\
\hline HS GPA & 3.42 & $3.64^{*}$ \\
\hline HS Rank & 73.7 & $83.1^{*}$ \\
\hline Math SAT & 609.7 & $598.2^{*}$ \\
\hline Verbal SAT & 546.4 & 548.1 \\
\hline SAT Total & 1156.1 & 1146.3 \\
\hline SES (DFG) & 4.6 & $4.1^{*}$ \\
\hline$\%$ Minority & 18.0 & $27.8^{*}$ \\
\hline
\end{tabular}

$*$ T-test significant at $\mathrm{p}<.001$.

Table 3. APPLICATIONS to ENGINEERING BY MINORITY STATUS by High School GPA, SAT scores, HS Rank

\begin{tabular}{|l|l|l|}
\hline & White & Minority \\
\hline HS GPA & 3.47 & $3.32^{*}$ \\
\hline HS Rank & 75.9 & $71.0^{*}$ \\
\hline Math SAT & 621.8 & $548.2^{*}$ \\
\hline Verbal SAT & 558.8 & $489.7^{*}$ \\
\hline SAT Total & 1180.6 & $1038.9^{*}$ \\
\hline SES (DFG) & 4.6 & $3.8^{*}$ \\
\hline$(n)$ & $(3727)$ & $(895)$ \\
\hline
\end{tabular}

*T-test significant at $\mathrm{p}<.001$ 
Given the significant differences found between the male and female, minority and white applicants it was important to determine whether those differences explain the different acceptance rates. Logistic regression was used to see whether the offers made differed significantly in terms of gender, minority status, socio-economic status of the school, high school GPA, SAT scores, or the term of application (as Rowan has become increasingly selective, which might be impacting different groups of applicants differentially). Offers made was the dependent variables $(0=$ no; $1=$ yes $)$; the independent variables were gender $(1=$ male, $2=$ female $)$; minority status $(0=$ white, $1=$ minority); socio-economic status of the high school district, the DFG statuses converted to numbers (1=low; $8=$ high); high school GPA; math SAT scores; verbal SAT scores; and term of application. In these analyses, the regression coefficients express the independent effect of each of the variables, when all of the other variables in the model have been controlled. Thus one knows that more women apply from low-income school districts, that on average they have higher GPAs than the male applicants, and that women are offered admission disproportionately. Is this because they are women, or because they come from low SES schools, or because of their relatively high GPA? By controlling for GPA and minority status and socio-economic status of the school district, one can determine whether gender has an effect on offers made independent of these other factors. Variables were entered in different stages, or models. The unstandardized regression coefficient allows one to trace how the effect of any particular variable changes when other variables are introduced into the model: thus in Model 1, the effect of gender that one sees is independent only of minority status; but in Model 2 , it is independent of minority status and socio-economic status of the high school district. The exponent in parentheses is similar to a beta coefficient in multiple regression analysis; it allows one to compare the effect of the variables in the equation to each other by reflecting the "odds" of someone with a given characteristic receiving an offer. If this exponent is 1 , it does not change the odds one way or the other; if it is less than one, it decreases the odds of receiving an offer; if it is more than one; it increases the odds of receiving an offer. The strength of the effect is reflected in its distance from 1. In Model 1 of Table 4, for example, the odds of receiving an offer are increased by being a woman (1.840) more than by being white (.512), although both are statistically significant at $\mathrm{p}<.05$.

Results of the analysis for offers are given in Table 4. The first model reflects what was shown above, that women are disproportionately given an offer, as are whites. Model 2 introduces the socio-economic status of the high school district. It too affects the odds of receiving an offer: applicants from lower SES districts are more likely to receive an offer, and its effect is somewhat stronger than that of either gender or minority status. But it is Model 3 which introduces more change in understanding of offers. Once high school GPA and SAT scores are entered into the equation, minority status does not have an independent effect on offers. That is, minorities receive fewer offers because of their lower GPAs and SAT scores. GPA has an effect on receiving an offer almost 7 times as strong as gender, and 14 times as strong as any of the other variables in the equation. That is, most offers are received on the basis of GPA. Being a woman still increases the chances of getting an offer, as does coming from a lower SES school district (much less than gender though). Having higher SAT scores helps just a little. Model 4 introduces the variable of term (year of the application), which reflects the increased selectivity of Rowan as it receives more and more applications. It is not a very strong effect though. 
Together, these variables explain over $76 \%$ of the variance $\left(r^{2}=0.764\right)$ in offers made. They also show that women are given an advantage in receiving offers, as women; but minorities are not. Further they show that SAT scores have been considerably less important considerations than high school GPA.

Table 4. LOGISTIC REGRESSION OF OFFERS MADE by Gender, Minority Status, SocioEconomic Status of School, High School GPA, SAT Scores, and Term of Application (Unstandardized regression coefficients; exponentiated ["odds"] regression coefficient in parentheses)

\begin{tabular}{|c|c|c|c|c|}
\hline & Model 1 & Model 2 & Model 3 & Model 4 \\
\hline Gender & $0.610(1.840)^{*}$ & $0.589(1.801)^{*}$ & $0.974(2.648)^{*}$ & $0.940(2.559)^{*}$ \\
\hline Minority Status & $-0.668(0.512)^{*}$ & $-0.700(0.496)^{*}$ & $0.183(1.200)$ & $0.189(.1 .208)$ \\
\hline $\begin{array}{c}\text { Socio-economic } \\
\text { Status of HS }\end{array}$ & & $-0.076(0.927)^{*}$ & $-0.290(0.748)^{*}$ & $-0.234(0.792)^{*}$ \\
\hline HS GPA & & & $2.668(14.417)^{*}$ & $3.386(29.534)^{*}$ \\
\hline Math SAT & & & $0.023(1.023)^{*}$ & $0.026(1.026)^{*}$ \\
\hline Verbal SAT & & & $0.024(1.024)^{*}$ & $0.025(1.025)^{*}$ \\
\hline Term & & 0.029 & & $-0.045(0.956)^{*}$ \\
\hline Nagelkerke $r^{2}$ & 0.025 & & & 0.732 \\
\hline$(n)$ & $(2551)$ & & & 0.764 \\
\hline
\end{tabular}

*Regression coefficient significant at $\mathrm{p}<.05$.

\section{Factors Influencing Yield}

The next analysis concerns who, among those who got offers, paid deposits. Again, a logistic regression model was used, with Deposits as the dependent variable (out of those given offers) ( $0=$ no; $1=y e s)$. Gender, minority status, school district's SES, high school GPA, math and verbal SAT scores, and term of application were the independent variables, as in the previous analysis. Results are presented in Table 5. Note that the $r^{2}$ values are low so the variables do not explain much of the variance in who pays a deposit.

Model 1 shows that whites are more likely to pay a deposit than minorities (as we have shown above), but that there is no significant difference in the rate of deposits paid by men or women. Interestingly, however, when one controls for the high school district's SES, gender does have a significant effect. This likely reflects an interaction between gender and high school district's SES: that is, women from lower and higher SES schools are less likely than men from those schools to pay deposits, while women from middle SES schools are more likely than men to do so. In all likelihood there is more than one dynamic influencing this (financial aid packages, offers from other schools, offers from other majors, etc.), which need further examination. Once SES is included in the model, it shows that men are more likely to pay deposits, as are whites, and those from lower SES schools. When GPA and SAT scores are added to the model, they add a little explanation to who pays deposits, but not a lot. Whites and men continue to be more likely to respond to offers with a deposit. Controlling for term of application (and offer) changes the analysis very little. 
Table 5. LOGISTIC REGRESSION OF DEPOSITS PAID by Gender, Minority Status, SocioEconomic Status of School, High School GPA, SAT Scores, and Term of Application (Unstandardized regression coefficients; exponentiated [“odds"] regression coefficient in parentheses)

\begin{tabular}{|c|c|c|c|c|}
\hline & Model 1 & Model 2 & Model 3 & Model 4 \\
\hline Gender & $-0.272(0.064)$ & $-0.310(0.733)^{*}$ & $-0.324(0.031)^{*}$ & $-0.323(0.724)^{*}$ \\
\hline Minority Status & $-0.541(0.582)^{*}$ & $-0.614(0.541)^{*}$ & $-0.704(0.494)^{*}$ & $-0.699(0.497)^{*}$ \\
\hline $\begin{array}{c}\text { Socio-economic } \\
\text { Status of HS }\end{array}$ & & $-0.157(0.855)^{*}$ & $-0.157(0.855)^{*}$ & $-0.153(0.858)^{*}$ \\
\hline HS GPA & & & $-0.275(0.760)$ & $-0.251(0.778)$ \\
\hline Math SAT & & & $-0.003(0.997)^{*}$ & $-0.003(0.997)^{*}$ \\
\hline Verbal SAT & & & $0.000(0.697)$ & $0.000(1.000)$ \\
\hline Term & & 0.034 & & $-0.002(0.998)$ \\
\hline Nagelkerke $r^{2}$ & 0.012 & & 0.045 & 0.046 \\
\hline$(\mathrm{n})$ & $(1695)$ & & & \\
\hline
\end{tabular}

*Regression coefficient significant at $\mathrm{p}<.05$.

\section{Where do the students come from?}

The next question was asked was "Where do our students come from?" It is known that counties immediately surrounding the college provide the largest number of applications and that nearly all applicants come from within the state. The socioeconomic distribution of applicants was not as clear. The distribution of applicants across the DFG is provided in Figure 2. Figure 3 is a percentage breakdown of applicants within each DFG grouping. Applicants tend to be predominantly middle to upper middle class with much lower application rates from districts in both the upper and lower ends of the socioeconomic spectrum. The percentage of female and minority applicants from within a socioeconomic group tends to be higher in the lower socioeconomic groups.

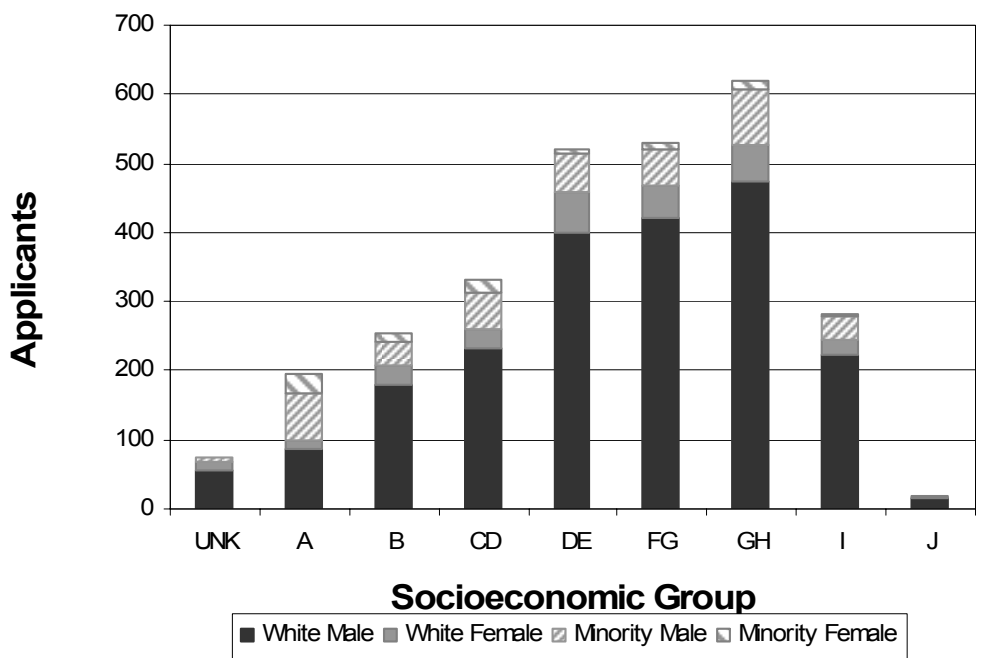

Figure 2. Distribution of applicants across socioeconomic groups to the engineering program (2000 to 2007). 


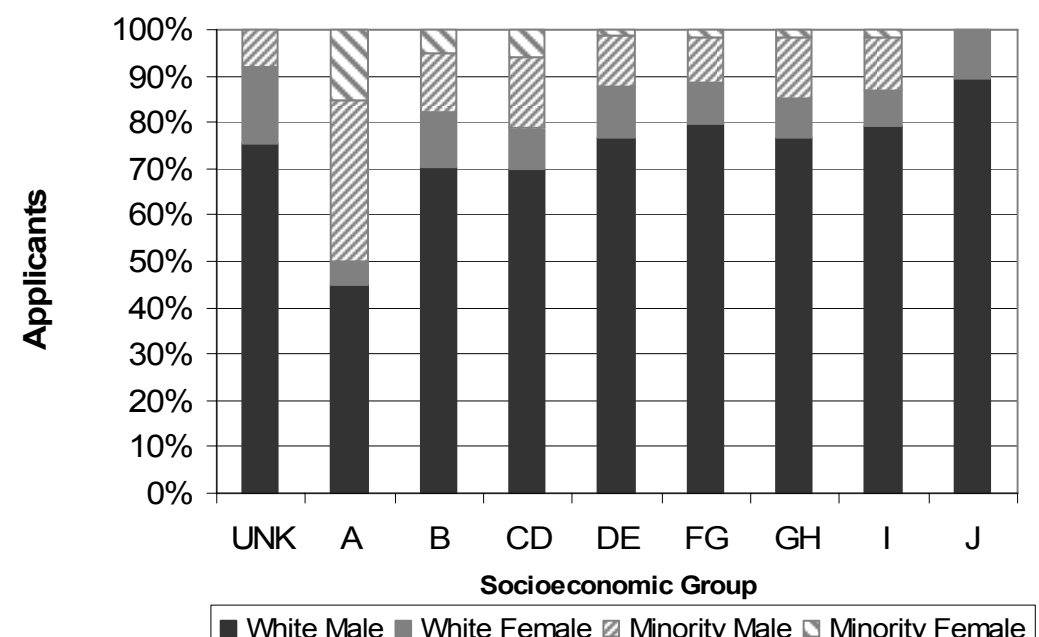

Figure 3. Distribution of applicants to the engineering program within socioeconomic groups (2000 to 2007).

\section{Analysis of Largest Feeder High Schools with Respect to Gender}

Table 6 is a list of schools from which the engineering program has received the largest number of applications (names are not included for privacy reasons). The break point for inclusion in this table was set to produce approximately 25 schools. The table also includes the socioeconomic classifications of the schools and a breakdown of the number of female applicants and the acceptance and yield rate for both genders. There is a wide range in the percentage of applicants who are female. The data was normalized to 30 applicants and then plotted against a Poisson distribution of the same mean to determine if the distribution of percentages of female applicants from the various schools agreed with statistical expectations. This plot is shown in Figure 4 and appears to be an acceptable match indicating no school is unduly influencing the results. There are no particular trends noted is this data that is different from those already described for the full data set. However, the data suggest some targeted opportunities to increase the numbers of applicants and the yields of female students as discussed later. These targeted efforts include comparison of the guidance strategies at schools with higher and lower percentages of female applicants and efforts to increase yields at schools providing significant numbers of female applicants but low yields. 
Table 6. Largest feeder schools based on number of applicants to engineering program (years $2000-2007)$.

\begin{tabular}{|c|c|c|c|c|c|c|c|}
\hline School & DFG & $\begin{array}{c}\text { \# of } \\
\text { Applicants }\end{array}$ & $\begin{array}{c}\% \\
\text { Female }\end{array}$ & \multicolumn{2}{c|}{$\begin{array}{c}\text { Offers Made }^{\text {a }} \\
(\%)\end{array}$} & \multicolumn{2}{c|}{$\begin{array}{c}\text { Deposits Paid } \\
(\%)\end{array}$} \\
\hline & & & & Men & Women & Men & Women \\
\hline & & & & & & & \\
\hline A & FG & 87 & 13.5 & 68.0 & 75.0 & 52.9 & 66.7 \\
\hline B & DE & 52 & 21.2 & 65.9 & 63.6 & 66.7 & 57.1 \\
\hline C & CD & 47 & 4.3 & 77.8 & 100 & 71.4 & 0 \\
\hline D & FG & 46 & 8.7 & 52.4 & 25.0 & 36.4 & 0 \\
\hline E & GH & 38 & 10.5 & 47.1 & 50.0 & 43.8 & 0 \\
\hline F & GH & 37 & 13.5 & 53.1 & 80.0 & 64.7 & 25.0 \\
\hline H & GH & 36 & 16.7 & 43.3 & 50.0 & 38.5 & 33.3 \\
\hline I & DE & 31 & 9.7 & 66.7 & 50.0 & 28.6 & 50.0 \\
\hline J & FG & 31 & 3.2 & 86.7 & 100 & 61.5 & 0 \\
\hline K & FG & 30 & 10.0 & 74.1 & 66.7 & 50.0 & 50.0 \\
\hline L & GH & 28 & 31.0 & 57.9 & 88.9 & 18.2 & 0 \\
\hline M & DE & 28 & 13.8 & 58.3 & 50.0 & 35.7 & 0 \\
\hline N & GH & 29 & 0 & 55.2 & - & 25.0 & - \\
\hline O & CD & 28 & 28.6 & 65.0 & 62.5 & 46.2 & 40.0 \\
\hline P & DE & 27 & 11.1 & 83.3 & 66.7 & 30.0 & 50.0 \\
\hline Q & DE & 27 & 7.4 & 64.0 & 100 & 43.8 & 50.0 \\
\hline R & I & 27 & 3.7 & 46.2 & 0 & 16.7 & - \\
\hline S & DE & 26 & 3.8 & 64.0 & 100 & 43.8 & 0 \\
\hline T & B & 26 & 23.1 & 75.0 & 66.7 & 40.0 & 0 \\
\hline U & FG & 24 & 8.0 & 72.7 & 100 & 25.0 & 100 \\
\hline V & DE & 24 & 8.3 & 90.9 & 100 & 65.0 & 100 \\
\hline X & GH & 24 & 12.5 & 71.4 & 100 & 40.0 & 33.3 \\
\hline & B & 24 & 25.0 & 66.7 & 66.7 & 58.3 & 25.0 \\
\hline & A & 24 & 12.5 & 61.9 & 100 & 33.3 & 46.2 \\
\hline
\end{tabular}

${ }^{a}$ Out of total applicants of each gender.

${ }^{\mathrm{b}}$ Out of total offers made to each gender.

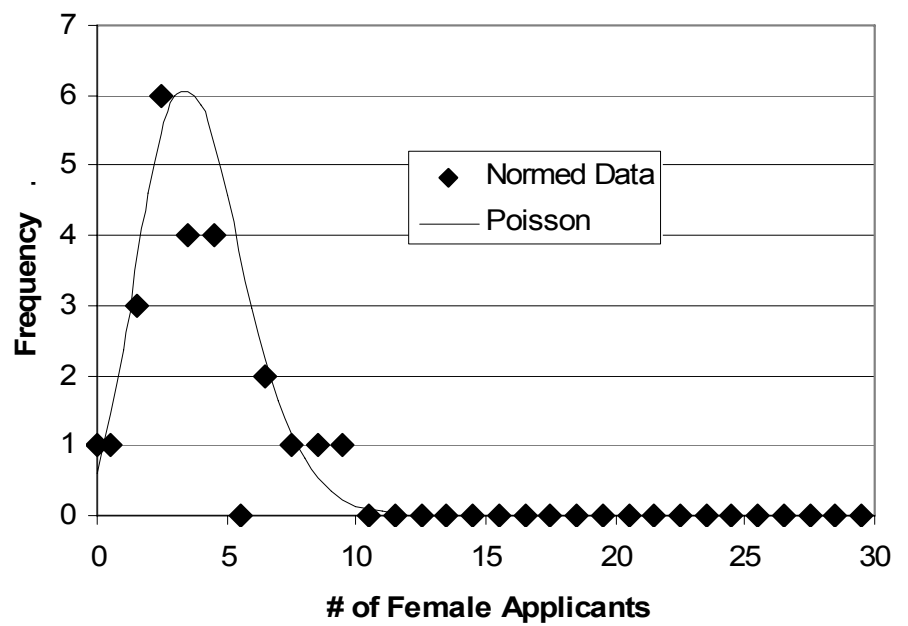

Figure 4. Normalized female applicant data fit to a Poisson distribution of equal mean. 


\section{Implications for Proposed Recruitment Strategies}

Informal discussions among faculty members have suggested a range of goals for female enrollments. An arbitrarily chosen target of $25 \%$ is sometimes discussed. Establishing a goal of an entering class in engineering to be $25 \%$ female, the college would need to bring approximately 17 more women into an entering class of 140 students than currently enroll (35 women total in a class of 140). Assuming the acceptance and yield rates remain unchanged this goal translates to the need to attract approximately 71 more female applicants each year. The average number of female applicants per year over the eight years of this study is 72 so effectively, with no change in acceptance rates or yield, the college needs to double the number of female applicants to reach such a goal; reaching the national average would require adding approximately 35 more female applicants per year.

It is not clear that $25 \%$ female enrollment is a realistic target in the shorter term. Nationally, a list of the top 20 schools reported as having the largest percentage female enrollment shows most are highly selective private institutions ${ }^{5}$. The proportion of women in engineering in these schools ranges from $28 \%$ to $46 \%$. These schools have a very different set of challenges and resources in the recruiting process than Rowan University has. Indeed, none of the schools listed resemble Rowan University in terms of enrollment, selectivity, and mission so as to serve as obvious models for recruitment initiatives. An analysis of female and minority enrollments sorted by size and type of school would be informative for schools to establish recruitment goals and to identify exemplary institutions to provide guidance or best practices.

When considering efforts to increase female or minority enrollments, there are three parts of the application process to consider. The first is the initial pool of applicants and how it could be modified. Second is the process of determining which applicants receive admission offers and the third deals with decisions those who receive an offer make (the yield). Suggested recruitment initiatives have been defined and implementation strategies are evaluated for success on the basis of the previous data analysis. The proposed initiatives are

- Improved/targeted advertising

- Adjustments to the admissions and financial aid processes

- Outreach to students at specific schools

- Informational exchanges with selected guidance counselors.

\section{Improved/targeted advertising}

While increasing the number of applicants to the college will increase the academic quality of the student body (assuming enrollment is held constant) it is not likely to increase the relative proportion of male and female students. However, analysis of the applicants indicates there is a "sweet spot" for yield. In Figure 5 the acceptance rate and yield rate has been plotted across the socioeconomic categories. While the rate at which the college accepts students is fairly constant across all the SES groups with the exception of lower acceptance rates from the high schools in the lowest categories, yields decrease in SES groups above CD. When considering yield for female applicants, the greater fall occurs beyond category FG (note that female data for $\mathrm{J}$ is 
based on a very small sample and was not plotted). As seen in Figure 3, categories B through DE have higher percentages of female and minority applicants. Increased advertising to the schools in categories below FG and particularly to schools in CD makes sense as these are the places from which the college has the highest yield. The analysis that has been performed allows one to identify schools in the CD SES grouping that have large high school classes relatively close to Rowan University that have not historically provided a large applicant pool. Marketing to these schools more heavily should increase the relative return on the marketing investment and has the added benefit of a higher percentage of underrepresented applicants. The impact of such effort is more likely to be on the margins rather than dramatic.

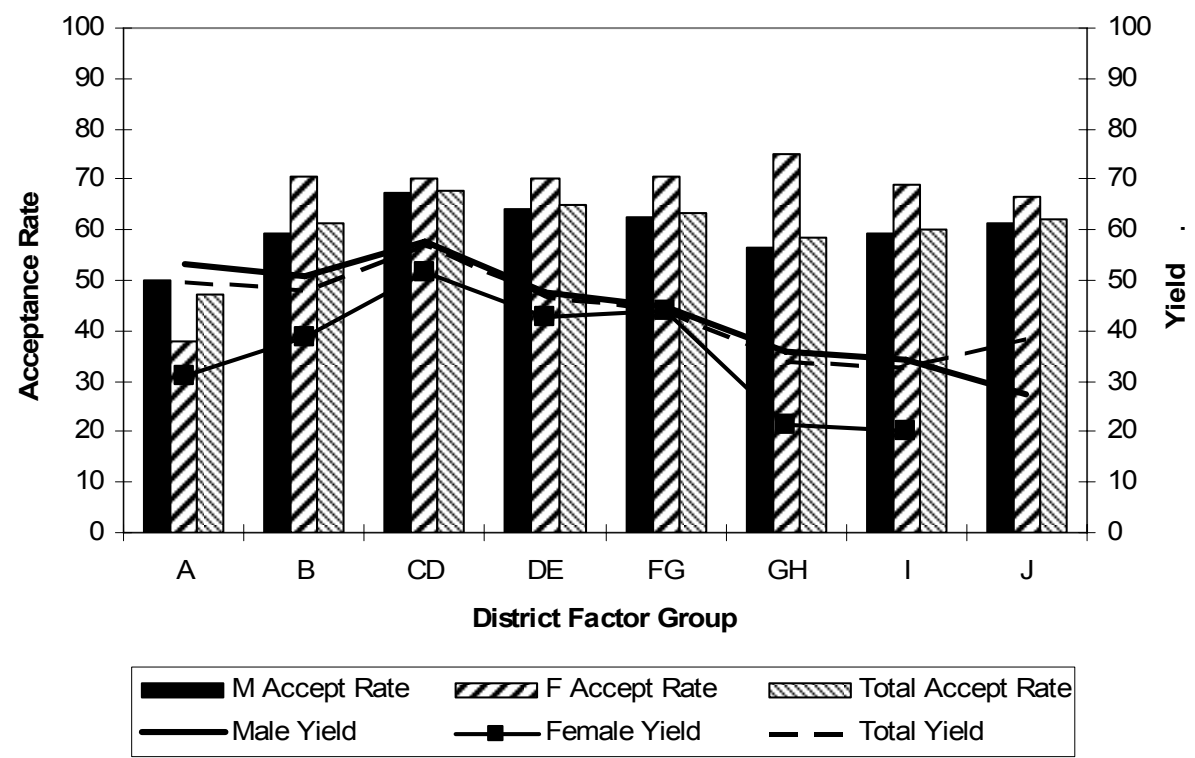

Figure 5. Accept rate and yield rate variation across socioeconomic groupings of schools.

\section{The admissions process}

As suggested by the preceding analysis, the process used to make offers to applicants includes measures to increase diversity. The process used to determine whether an applicant is accepted begins with consideration of combined Math and Verbal SAT score and class ranking. Applicants with a combined SAT score and class rank above target values are automatically accepted (a target GPA value is used in place of class rank for schools that do not rank their students). Typically in late January the number of accepted students in each program is compared to acceptance goals established based on historic yield in order to provide desired class size. As required to meet these goals, additional offers are made. These selections are made by considering options such as accepting students with slightly lower SAT scores or high school class ranks or GPA than those who were previously admitted. The additional offers continue throughout spring in order to carefully manage class size.

As shown in the earlier analysis, this process results in offers going to proportionally higher percentage of female applicants once GPA and SAT score has been controlled for. As shown in Table 3, while SAT scores for male and female students are very close, female applicants have a 
higher average GPA. It was also shown that white applicants have a higher GPA than minority applicants (Table 4) however the difference is not as large as the difference based on gender. GPA is the single most important determining factor in who receives an offer (Table 5). A small reduction in the required GPA for admittance could then result in the acceptance of more minority candidates without overly impacting the advantage currently found for female applicants.

Increasing the number of minority students in the engineering college has an additional barrier not present for female applicants. The acceptance rate for minority applicants is greatly impacted by the use of SAT scores in the application criteria. While no large differences were found in SAT scores based on gender of the applicant, as shown in Figure 6, there are significant differences based on race. White applicants have a mean total SAT score just below 1200 consistently across all of the socioeconomic groups. Minority applicants consistently have a lower total SAT across all socioeconomic groups with the lowest scores recorded in the lowest socioeconomic groups. A higher percentage of applicants in the lowest three socioeconomic groupings are minority. When minority applicants were further subdivided into ethnic groups, mean SAT scores for each group were found to be lower than the mean for white applicants (Table 7). Although, it was shown that GPA has historically been the more important factor determining who receives an offer, clearly a larger percentage of minority applicants will not meet an SAT-based admissions criterion. In the early years of the college some students were accepted into engineering on a probationary status which provided an option for minority (and any other) student falling close to but below the admissions standards. However, this option was discontinued as it was found that almost none of the probationary admits were able to later gain acceptance into the engineering college based on their college performance. This would suggest that abandoning or lowering SAT-based criteria by a large amount would not serve the students or the college well. However, the differences in GPA between white and minority applicants do not appear to be as large as the SAT differences. Increasing the weighting given to GPA or class rank, while maintaining a lower bound on SAT score, could conceivably increase the number of minority students accepted. Prior to making a significant change to the admissions policy further study of the correlation between SAT, high school GPA, and success in our engineering programs would be needed.

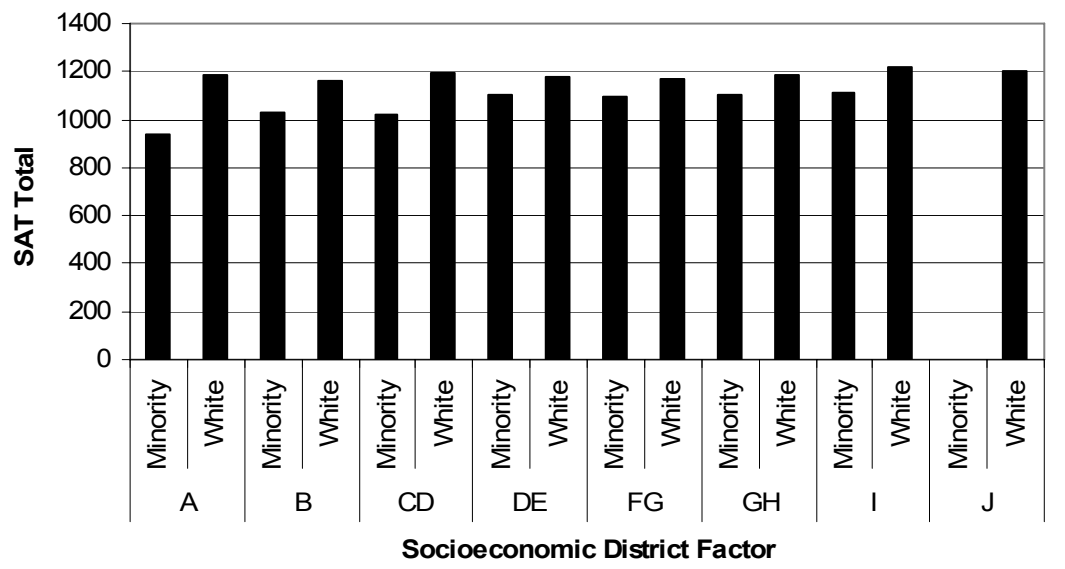

Figure 6. Mean total SAT score for white and minority applicants across socioeconomic groups. 
Table 7. Mean GPA high school class rank, and SAT scores of applicants by ethnic background.

\begin{tabular}{|l|c|c|c|c|c|}
\hline & White & $\begin{array}{c}\text { African- } \\
\text { American }\end{array}$ & Hispanic & Asian & $\begin{array}{c}\text { Native- } \\
\text { American }\end{array}$ \\
\hline Offers & $63 \%$ & $27 \%$ & $36 \%$ & $43 \%$ & $29 \%$ \\
\hline HS GPA & 3.47 & 3.18 & 3.35 & 3.41 & 3.04 \\
\hline HS Rank & 75.9 & 69.2 & 71.4 & 73.2 & 52.4 \\
\hline Math SAT & 621.8 & 501.4 & 548.0 & 595.6 & 565.0 \\
\hline Verbal SAT & 558.8 & 462.9 & 503.2 & 504.8 & 505.0 \\
\hline SAT Total & 1180.6 & 964.3 & 1051.3 & 1100.4 & 1070.0 \\
\hline (n) & $(3727)$ & $(319)$ & $(266)$ & $(303)$ & $(7)$ \\
\hline
\end{tabular}

\section{Financial aid considerations}

The low yield rate for underrepresented applicants is problematic for this institution. As part of a public university, the college of engineering does not have the ability to offer beefed-up financial aid packages to any particular group of students. Financial aid through loans and scholarships is strictly based on a financial need evaluation. In contrast, some private colleges are able to use financial aid offers to shape the make-up of the student body. However, the University Foundation is a distinct entity established to manage donor support to the university. The college could work through its various Industry Advisory Boards to establish a scholarship fund for underrepresented groups. Funding of the program would be solicited from the engineering community or other donors interested in diversity in the engineering workforce. These scholarships could be used to sweeten the offers made to applicants from targeted groups. Ideally these would not be one-shot scholarships but four-year continuing scholarships. This recommendation is consistent with Commission on the Advancement of Women \& Minorities in Science, Engineering, \& Technology Development (CAWMSET) recommendations that national and state programs increase "multiple grant mechanisms rather than loans to include scholarships, fellowships, and internships" as a means to increase enrollment and retention of underrepresented groups ${ }^{11}$.

\section{Outreach to students at specific schools}

Review of the data from the schools providing the largest number of applicants (Table 6) reveals several opportunities for targeted efforts. The school presented as School K is an interesting case. The school is classified as GH for socioeconomic conditions putting it outside the band in which the college experiences the greatest yields. However, $30 \%$ of the applicants from this school are female and of these female students, $80 \%$ receive an offer from the engineering college. Clearly there is a highly qualified pool of female students at this school with an interest in engineering. Unfortunately, not a single female student from the school has actually paid a deposit to the engineering college at Rowan University (note that yield of male students from this school are also low at $18.2 \%$ ). An obvious step is to make some recruiting visits to this school in order to sell the programs offered directly to the students. Involving students from 
Society of Women Engineers or Engineers without Borders may be effective, as these groups both have a high female participation rate at the college.

A second case for consideration is School C, a campus located very close to the college campus that has provided the third highest number of applicants to the engineering college. The college has formal articulation agreements with the school and is closely tied to the school through summer programs related to the National Engineering Academy and Project Lead the Way. The yield from this school is the highest of any in the state yet only a very small percentage of the applicants have been female and none have elected to attend the college in engineering even though women are represented in their high school engineering specific classes. Relationships with this school are very strong and this represents another location for direct recruitment to better communicate what the college offers.

Review of Table 6 reveals several other schools with low percentage of female applicants although ties to the college may not be as strong. Indeed no female students from three of the top five schools based on number of applicants have elected to enroll in the college. Increasing female applicant numbers from these schools may be a matter of more direct recruiting efforts. Anecdotal data and the college's experience as it has matured and expanded recruitment into northern parts of the state have suggested often the barrier to overcome is getting the first students to apply and attend from a particular school. Once this occurs, word trickles back to the high school and recruiting becomes easier.

For a period of years a regular program of faculty visits to many high schools was in place. However as the college matured and other demands on faculty time increased, most of these visits were abandoned. A more targeted approach based on previous successes and specific schools identified as having potentially untapped pools would be more efficient and better received by participants, particularly if there is follow-up to measure the success of the efforts.

\section{Informational exchanges with guidance counselors}

Guidance counselors play a key role in the determining what courses students take in school and what college they attend. The comparative data from the largest contributors to the application pool reveal recruitment initiatives that need to be considered. For example one would want to meet with the guidance counselors and study the curriculum at the schools where recruitment of female students is already successful to learn what is happening at that school leading to the success. A school from which a large number of male applicants are found but with few female applicants (e.g. School C) could require a program designed to show women that engineering is a viable option. For such a school it may be a matter of educating the guidance counselors. As noted in ASEE's publication Prism ${ }^{4}$

Even if engineers succeed in gaining the interest of young women, African-Americans and Hispanics, there's often another hurdle to overcome: skeptical guidance counselors, teachers and parents-influential folks whose judgments are also skewed toward the negative by hoary stereotypes and limited information. "We need to place more emphasis on counselors, teachers and parents because not only do they often not push them into science and math, they push them away," Dean Burge says. Adds Shanahan: "We are 
failing to get the word out to them. They are not leveraged as much as they could be." Burge suggests that each of the nation's 344 schools of engineering should form a "mentor" relationship with at least one local high school to help it improve its teaching of STEM subjects. That would also be a way to educate more teachers and counselors on the value of engineering degrees, he says. "It could help put more folks in the pipeline."

Indeed, the college has established such relationships with two schools. The first is School C which, as noted above, has the highest yield of the large applicant pool schools. The second, smaller school was not included in Table 6 . There have been 20 total applicants ( $30 \%$ female) with an $80 \%$ yield rate ( $75 \%$ for female, $82 \%$ for male) from this school. Clearly direct ties to schools are an effective way to increase yield.

School C and School N provide a contrast in success in recruiting female students. Both schools fall within the CD socioeconomic "sweet spot" for yield. In contrast to School C, there are no particular ties with School N. However the number of female applicants and the yield are far above the college's average. It would be instructive to visit with the math, science, and guidance departments at this school to determine if there are specific initiatives or activities occurring at this school that could be implemented at other places.

\section{Outreach to community colleges}

Outreach to community colleges was not one of the recruitment strategies initially under consideration. Most of the students entering the engineering program enter as freshmen and follow a traditional four-year track. SAT scores play a key role in admittance to the program. However, there is an alternate track into the college. Students may transfer into the various engineering programs from a community college. These students are evaluated strictly on the college-level work they perform at the community college, particularly in their math and science courses. SAT scores (or any part of the high school record) are not considered for these transfer students. A recently implemented state-wide program that offers two-year scholarships to community college students that can be extended for an additional two years to complete a bachelors degre ${ }^{12}$ might increase the importance of community college outreach.

The college may be able to increase the number of minority students entering engineering through the transfer process by expending more recruiting efforts directly to the community college. An example of this would be offering open houses specifically geared toward community college students similar to those currently run targeting high school students. In addition closer ties to the community colleges might be established through articulation agreements and the perhaps the establishment of working groups composed of representatives of the four year programs and the engineering science programs at the community colleges. Guidance counselors at the predominantly urban high schools also need to be aware this alternative route into majors with restrictive admittance criteria. Clearly there are minority students with an interest in engineering because the applications are there. However, too many of the applicants do not meet the entrance criteria. It is not known how many of these applicants stop pursuing engineering at that point because they are not aware of the community college option. 


\section{Conclusions and Recommendations}

An eight year record of applicants to the college of engineering to Rowan University was analyzed to find trends related to underrepresented groups. Trends considered included application rates, high school performance and standardized test scores, and socioeconomic conditions of the high school the applicants were from. The analysis was used to refine plans for specific recruiting initiatives intended to increase the population of underrepresented groups in the college. In particular the investigators were interested in identifying locations or socioeconomic groups where the efforts might have the greatest chance for success. Based on the analysis, the following recommendations are made.

- The college should increase its efforts to recruit from schools from specific socioeconomic groupings, as these groups have historically resulted in the largest yields and have relatively large percentage of underrepresented applicants.

- The college should work with the University Foundation to establish and fund a scholarship program for students from underrepresented groups offered admission to the college. The proposed scholarships should be ongoing rather than one-year offers and are intended to address the historically lower yields the college has from the underrepresented population.

- Direct recruitment visits should be made to selected schools with large numbers of applicants showing disparity between male and female application numbers and/or yield numbers. There should be future follow-up to measure the effectiveness of the visits.

- Stronger ties to guidance departments at specific schools should be established for two purposes. In some cases the guidance departments need to become more aware of the opportunities and need for underrepresented groups in engineering. In other cases the college is interested in discovering the practices employed at certain schools from which success has been shown placing underrepresented populations into engineering programs. These practices need to be shared with schools where such success is not evident.

- Establish closer ties to community colleges where there may be a pool of students whose test scores disqualified them from initial acceptance into engineering programs but have proven their abilities at the community college.

- The college may want to consider a reduction on the weighting given to SAT scores in the admissions process or establish a system that accepts lower SAT scores with increasing GPA.

Information not specifically addressed in this study but of importance to future recruiting efforts is determining where the students who decline admission offers go. This would improve understanding of the factors that lead to their decisions not to attend. Therefore an additional recommendation is that the college pursues this data. The most efficient method is through surveys conducted by the admissions office. An alternative approach may be possible through high school guidance departments. This would again emphasize the value of ties to this group.

It is important that colleges establish realistic recruitment goals for underrepresented groups. Better knowledge of how populations of underrepresented groups vary among types and sizes of engineering programs would be informative for establishing these goals. It is hoped that this work can be part of a dialogue regarding this issue. 
The next step for this program is refinement and implementation of the above recommendations. As initial charges will be incremental, the results of the efforts must be tracked over a period of years to evaluate their effectiveness.

\section{Acknowledgements}

The work presented in this paper was made possible by funding provided by the Engineering Information Foundation. The results do not necessarily reflect the views or opinions of the funding agency. Their support in this work is appreciated.

\section{References}

1. Kiplinger's Personal Finance, February 2007. http://www.kiplinger.com/tools/colleges/.

2. U.S. News and World Report, "America's Best Colleges," August 27, 2007, http://colleges.usnews.rankingsandreviews.com/usnews/edu/college/rankings/rankindex_brief.php

3. Hartman, H. and M. Hartman (2006). "Leaving Engineering: Lessons from Rowan University's College of Engineering," Journal of Engineering Education, American Society for Engineering Education, January, 2006, pp $49-61$.

4. Grose, T. K. (2006). "Trouble on the Horizon," ASEE Prism, 16:2.

5. ASEE (2006). Profiles of Engineering Colleges, American Society for Engineering Education.

6. New Jersey Department of Education (2007). http://www.state.nj.us/education/finance/sf/dfg.pdf

7. Busch-Vishniac, I. J. and J. P. Jarosz (2004). "Can Diversity In The Undergraduate Engineering Population Be Enhanced Through Curricular Change?" Journal of Women and Minorities in Science and Engineering, $10: 3$, pp $50-84$.

8. The Council of Chief State School Counselors, "New Jersey Profile Of Hiv, Std, And Teen Pregnancy," Retrieved on January 11, 2008 from http://www.ccsso.org/content/pdfs/SPNEWJERSEY.pdf.

9. National Science Foundation (2007). Women, Minorities and Persons with disabilities in Science and Engineering: 2007, Table B-9 p. 35, http://nsf.gov/statistics/wmpd/pdf/december2006updates.pdf.

10. Seymour, E. and N. Hewitt (1997). Talking About Leaving: Why Undergraduates Leave the Sciences. Boulder, CO: Westview Press.

11. CAWMSET (Congressional Commission on the Advancement of Women \& Minorities in Science, Engineering, \& Technology Development), 2000. Land of Plenty: Diversity as America's Competitive Edge in Science, Engineering \& Technology. Washington, DC: National Science Foundation.

12. New Jersey Student Tuition Assistance Reward Scholarship (NJ STARS). Viewed on January 14, 2007 at http://www.njstars.org/.

13. http://www.collegeboard.com/about/index.html, viewed February 22, 2008. 